\title{
Positively Shifting the Mindset in Construction Using Non-Biodegradable Materials for Sustainable Construction: An Experimental Study
}

\author{
Faheem Memon \\ faheemquest@hotmail.com \\ Quaid-e-Awam University of Engineering Science \& Technology \\ Nawabshah, Pakistan
}

\begin{abstract}
Disposing of the non-biodegradable material, scrap Tire rubber specifically, has always been a bone of contention for the municipalities around the world. Not only the land that it covers is the major issue, but also the environment is always at risk because the scrap tire being non-biodegradable, takes ages in decomposition. It is always prone to fire, which may cause disastrous situation around as it is not so easy to extinguish the scrap tire fire by whatever the resources available to the firefighters. To deal with this modernday issue which rapidly became a serious concern of many governments in terms of social, economic \& environmental sustainability, many researches started working on the effective use of scrap tire rubber by using it in different infrastructure elements, for instance, road pavements, waterproofing of underground utilities, shotcrete for tunnel wall lining, floor coverings of the playgrounds. Keeping in mind the sustainability issues, this study was conducted to assess the change in the fundamental structural properties of the concrete by mixing scrap tire rubber as an additive material. Four batches of the concrete were designed to be tested in the laboratory with the first batch as plain concrete with no scrap tire rubber to be kept as a reference point, $10 \%, 20 \%$ and $30 \%$ addition of scrap tire rubber by weight of cement. Results showed drastic improvement in Cylinder Crushing Strength, Modulus of Elasticity, the Poisson's ratio and the Ultimate Flexural Strength of beams.
\end{abstract}

Keywords: Scrap tire rubber; Concrete; Ultimate flexural strength; Modulus of elasticity; Poisson's Ratio

\section{INTRODUCTION}

Fibre-reinforced concrete is a composite material consisting of cement paste, mortar or concrete with the fibre of asbestos, glass, plastic, polypropylene, steel etc. such a fibre reinforcement may be useful under explosive loading where high strength in tension zone and reduced hair cracking is desired. Different fibres are used for reinforcing concrete and still research is underway to introduce some new and better ones.

Steel (carbon, stainless), glass (alkali-resistant) has a higher value of elastic moduli, and they contribute both to impact resistance and to flexural strength. Again, natural fibres like asbestos and vegetable fibres and polypropylene improve impact resistance but flexural strength may remain unaffected. A few of the advantages of such type of concrete are; high tensile and impact resistance, high compressive strength, very good and satisfactory flexural strength, increase in ultimate load carrying capacity, improvement of ductility, shear strength, torsion strength, splitting resistance, bearing 
strength, resistance against wear and abrasion, high resistance to freezing and thawing and fatigue loading.

The compressive strength of concrete is very high but due to its brittleness, it cannot resist sufficient tensile stress. Therefore, steel bars are used to strengthen concrete in situations where tensile stresses are developed. Another form of reinforcement is random dispersal of short, discontinuous and discrete fine fibres called fibre reinforcement. The fibre can be imagined as an aggregate with an extreme deviation in shapes from the rounded smooth aggregate. The fibres interlock and entangle around aggregate particles and considerably reduce the workability while mix becomes more cohesive and less prone to segregation. The fibre suitable for reinforcing the concrete has been produced from steel, glass and organic polymers.

In contrast to reinforcing bars in reinforced concrete which are continuous and carefully placed in the structures to optimize their performance, the fibres are discontinuous and are generally randomly distributed throughout the concrete matrix. Thus, the reinforcing performance of steel fibres, for example, is inferior to that of reinforcing bars. Also, the fibres are likely to be more expensive than conventional steel bars, thus, fibre reinforced concrete is not likely to replace conventional reinforced concrete. However, the addition of fibres makes the conventional plain concrete more versatile, more flexible in method of production and more competitive as a construction material.

Essentially, fibres act as crack arrestors, restricting the development of cracks and thus transforming an inherently brittle matrix, i.e., Portland cement with its low tensile and impact resistances into a strong composite with superior cracks resistance, improved ductility and distinctive post-cracking behaviour before failure. Steel fibres are probably the best suited for structural applications. Due to the superior properties like increased tensile and bending strengths, shear and torsional strengths, improved ductility, resistance to cracking, high impact strength and toughness, spalling resistance and high energy absorption capacity, fibre-reinforced concrete has found special application in hydraulic structures, airfield pavements highways, bridge decks, heavy-duty floors and tunnel linings.

Since all the types of fibre tried so far are quite expensive to achieve economy of construction but without sacrificing the better and improved strength properties of fibre reinforced. Initially, at Quide Awam University of engineering Science \& Technology, this was done by micro-concrete using machine shop scrap. However, the study that is being presented in this paper has an enhanced scope of the addition of scrap tire rubber with normal concrete consisting of Ordinary Portland Cement, hill sand and coarse aggregates.

\section{LITERATURE REVIEW}

In general, the concrete used with fibre reinforcement requires higher cement concrete, lower coarse aggregate content and smaller size of coarse aggregate. A very large number of investigators have conducted systematic research on various aspects of fibre reinforced concrete for more than three decades. A few of application areas in which significant field trials took place include overlays for bridge decks and pavement (highway and airfield), mining and tunnelling application, slope stabilization, refractory application, concrete repair, industrial floors and precast concrete products. 
Samarai, 1974 studied experimentally the influence of fibres upon crack development in reinforced concrete subject to uniaxial tension. Gopalan et al., 1974 studied the effect of steel fibres on the strength of concrete beams. Aligned continuous fibres, aligned discontinuous fibres and random discontinuous fibres were within the domain of their extent of experimental investigations. The durability of fibre with the cement matrix is one of the most important aspects. Therefore, Hannant et al., 1975 undertook to assess experimentally the resistance of steel fibre to corrosion in normal weight and lightweight concrete cylinders in the cracked state and also studied the performance of fibres in normal grade concrete beams exposed after initial loading which induced cracks with widths of $0.1 \mathrm{~mm}$ to $0.3 \mathrm{~mm}$. The cylinders were placed on three sites covering relatively mild exposure, marine conditions and polluted industrial atmosphere. Observation for 4.75 years suggests that the corrosion of fibres within the concrete is unlikely to cause major problems. The cracked beams were exposed to the marine environments for eleven months during which significant carbonation and fibre corrosion occurred. The failure loads of the specimens tested at this age did not decrease below the initial cracking loads. The failure of steel fibre reinforced concrete composites is generally attributed to the failure of the bond between fibres and matrix. Thus, the strength of the fibres is not fully utilized. Attempts have been made to improve the efficiency of fibre reinforcement by increasing the shear strength of the fibre-matrix interface by chemical or mechanical means as well as by aligning the fibres in the direction of the principal tensile stress. The influence of increased bond strength by chemical or mechanical means is generally measured by a pull-out test on a single fibre. The peak load required to pull out fibre is often expressed at average bond strength by dividing its value by the embedded surface area. The post cracking tensile strength of fibre reinforced concrete has been studied by Gasparini, et al., 1989. Nammur George et al. 1989 investigated the bond stress for fibre reinforced concrete based on the bond stress-slip relationship.

\section{EXPERIMENTAL DETAILS}

The behavior of concrete is affected by different parameters. Therefore, before starting the project it is necessary to decide the parameter of the study. Since, it is supposed to compare the properties of the concrete, mixed with different proportions of fibre fragments, hence the percentage of fibre fragments in the mix is kept as variable

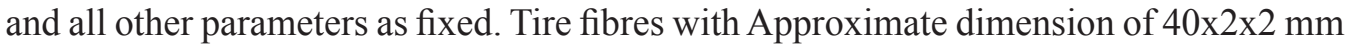
from the sidewall of the scrap tire were prepared for the study reason.

\subsection{Ratio of Tire fibre}

It is expected that Tire fibre scrap would increase the strength of concrete with an increase of percentage in mix. So, the ratio of $10 \%$ to $30 \%$ of tire fibre is used.

In this regard, a standard mix with a design strength of $15 \mathrm{~N} / \mathrm{mm}^{2}$ is taken and the effect of the ratio of Tire fibre added as reinforcement, on the fundamental structural properties have been investigated. The ratio of this fibre is $10 \%$ to $20 \%$ to $30 \%$ by weight of the cement. The tire fibre is added randomly during the mixing of the ingredients of the fresh concrete. 


\subsection{Mix Proportions}

To get comparable results, any type of concrete can be used, e.g., Normal concrete (i.e., with fine and coarse aggregates) or micro concrete (i.e., with fine aggregate only). For this study, normal concrete is used, prepared with fine sand (i.e., red hill sand) passed through No: 16 sieve and coarse aggregate passed through $10 \mathrm{~mm}$ sieve mixed with cement and potable water. The ratio of mix is kept as 1: 2: 4: by weight (i.e., 1 for the cement, 2 for the fine aggregates and 4 for the coarse aggregates) and w/c ratio is 0.5 .

\subsection{Compaction}

The compaction of concrete may result in large variations between selected batches, if not maintained properly. The compaction is usually done by table vibrators in the' laboratories. In our structures laboratory, the available vibrator is table type and its maximum intensity is 10 oscillation $/ \mathrm{min}$.

To get the same degree of compaction in all the batches, the vibrator was maintained at 5 oscillation/min. and kept it on for 20 minutes.

\subsection{Curing}

As discussed earlier in detail, that the strength of concrete increases with age if properly cured. Since for design purposes, 28-day strength is used, therefore, all the batches were submerged in the pond for 28-days.

\subsection{Cubes}

Cubes are used for determining crushing (compressive) strength of concrete. However, they contribute to determining the modulus of elasticity and Poisson's ratio too. The latest size as prescribed by BS 1881 is $100 \mathrm{~mm} \times 100 \mathrm{~mm} \times 100 \mathrm{~mm}$. Due to the restraining effects of platens, it is expected that the results obtained at such size are more reliable than any other size at uncharged factors.

\subsection{Cylinders}

Cylinders are used especially for determining the indirect tensile strength tests, and on the other hand, they help a lot to determine the modulus of elasticity. Cylinders give tensile strength by using cylinders of $150 \mathrm{~mm}$ height and $75 \mathrm{~mm}$ diameter.

\section{EXPERIMENTAL PROCEDURE}

The experimental procedure is different for different types of tests. For this study, different tests were performed and various purposes served by these tests are as follows;

\subsection{Compression Tests for Crushing Strength}

For compression tests, the cube is concentrically placed between the platens of universal load testing machine and then load is applied gradually till the cube is crushed. The ultimate load at the crushing failure is divided by the cross-sectional area of the cube to give ultimate compressive stress. At least three cubes from each batch are crushed and tested for values. Average of the three is taken as the representative value of ultimate compressive stress. 


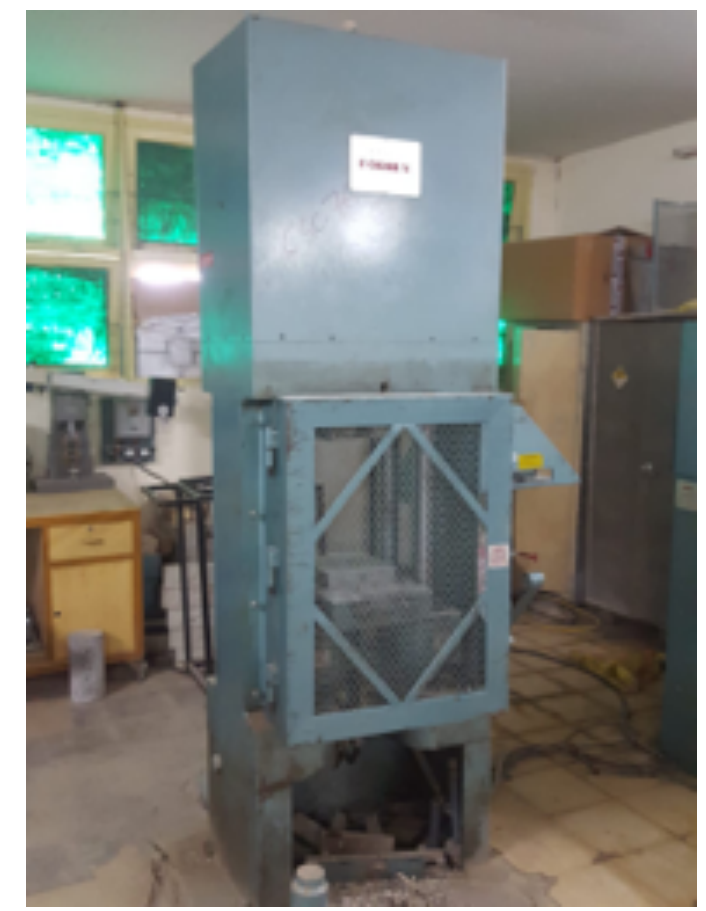

Figure 1: Forney Universal Load Testing Machine

\subsection{Test for Modulus of Elasticity}

4.2.1 Immediately before the test, the cube crushing strength of concrete is determined and one-third of the value is taken as Cm, i.e. Elastic limit stress. DEMEC pads are stuck on the opposite sides of cylinder specimen with the help of Magic Depoxy steel (or Araldite) in such a fashion that gauge points are symmetrically about the middle of the specimen. DEMEC gauge is used to measure the strain at different loading stages.

4.2.2 Initially, no-load readings of the gauge are noted and this specimen is placed under compression in the universal load testing machine, the load is gradually applied up to $(\mathrm{Cm})$. The load is maintained here for one minute approximately and DEMEC gauge readings are measured on either side of the specimen. The load is then released to measure the strain values again before the second step of loading.

4.2.3 The load is then reapplied at the same rate until the average stress of $(\mathrm{Cm}+1)$ is reached. Strains are measured once again and load is hold up till the gauge readings are taken safely. The no-load readings are again noted after releasing loads.

4.2.4 The load is applied once again at the same rate and strains are measured at a point when the average stress of $(\mathrm{Cm}+2)$ is reached and after releasing the load, the value of strain is measured.

4.2.5 The load is applied fourth time at the same rate and DEMEC gauge readings are taken in approximately ten equal increments of stresses up to $(\mathrm{Cm})$.

Modulus of elasticity, $E=\frac{\text { Stress }}{\text { Strain }}$ 
Where Stress $=\frac{\text { Force }}{\text { Cross sectional area of a cylinder }}$

For each case and finally the average of all represents the actual modulus of elasticity for that particular concrete mix.

\subsection{Test for Poisson's Ratio}

Tests for Poisson's ratio are performed on cubes, keeping in mind the principle that axial strain is always accompanied by lateral strain. For the very purpose, DEMEC pads are stuck on two opposite sides of the cube in a set of four, two are horizontal and two are vertical. They are kept at the same distance from the centre of the cube. The strain gauge readings are measured horizontal and vertically simultaneously for lateral strain and axial strain respectively.

The load is applied in the same manner as was done for the computation of modulus of elasticity.

Poisson's Ratio, $\quad v=\frac{\text { Lateral micro strain }}{\text { Axial micro strain }}$

\section{GENERAL DESCRIPTION}

In all Twelve Cubes were tested for 4 batches of concrete with $0 \%, 10 \%, 20 \%$ \& $30 \%$ tire rubber.

Poisson's Ratio, as well as Cube crushing strength, were determined. Twelve Cylinders were tested to find the modulus of elasticity and cylinder crushing strength. Four beams with no reinforcement Steel bars were tested by applying a single point load at the center. The effective span of the beam was $900 \mathrm{~mm}$ and the load was applied gradually with small increments till failure; the purpose was to determine tensile strength and its improvement due to the presence of Tire rubber.

\section{SUMMARY OF RESULTS}

Table 1: Summary of Results

\begin{tabular}{|c|c|c|c|c|}
\hline \multirow[t]{2}{*}{ Property } & \multicolumn{3}{|c|}{ Fibre Percentage } & \multirow[t]{2}{*}{ Remarks } \\
\hline & $10 \%$ & $20 \%$ & $30 \%$ & \\
\hline $\begin{array}{l}\text { Cube Crushing Strength } \\
\mathrm{N} / \mathrm{mm}^{2}\end{array}$ & $*$ & $*$ & 24 & Concrete Grade M15 \\
\hline $\begin{array}{l}\text { Cylinder Crushing } \\
\text { Strength } \mathrm{N} / \mathrm{mm}^{2}\end{array}$ & 18.35 & 21.26 & 28.41 & Concrete Grade M15 \\
\hline $\begin{array}{l}\text { Modulus of Elasticity } \\
\mathrm{KN} / \mathrm{mm}^{2}\end{array}$ & $*$ & 28 & 36.05 & \\
\hline Poisson's Ratio & 0.382 & 0.37 & 0.1185 & $\begin{array}{ll}\text { B/W } & \\
1.1 & \text { For High Strength } \\
1.2 & \text { For Weak Mixes } \\
\end{array}$ \\
\hline $\begin{array}{l}\text { Ultimate Flexural Stress } \\
\mathrm{N} / \mathrm{mm}^{2}\end{array}$ & 4.9 & 8.69 & 12.42 & $\begin{array}{l}\text { Increasing with the fibre } \\
\text { increase }\end{array}$ \\
\hline
\end{tabular}

* Due to experimental inaccuracies, some of the results were discarded. 


\section{CONCLUSION}

- Cube crusting strength does not show appreciable improvement of strength except when the Tire Fibre ratio is in the range of $30 \%$.

- Cylinder crushing strength shows substantial improvement with the increase of the ratio of Tire Fibre at every percentage.

- Modulus of elasticity also shows a drastic increase only in the case of 30\% Tire Fibre.

- Poisson's ratio decreases quite a lot when the Tire Fibre is 30\%. Otherwise, at lower percentage, the effect is negligible.

- The improvement of ultimate flexural stress is quite good at every percentage.

\section{REFERENCES}

Gasparini, D. A., Verma, D. \& Abdallah A. Post cracking Tensile Strength of Fiber Reinforced Concrete. ACI's Materials Journal, Volume 86, Issue 1, 10-15.

George Nammur Jr. \& Antoine E. Naaman. (1989). Bond Stress Model for Fiber-Reinforced Concrete Based on Bond Stress-Slip Relationship. ACl's Materials Journal, Volume 86, Issue $1,45-57$.

Hannant, D. J. (1976). Additional data on fiber corrosion in cracked beams and theoretical treatment of the effect of fiber corrosion on beam load capacity. RILEM, Volume 2, 533-538.

Rajagopalan, K., Parmasivam \& Ramaswamy G. S. (1974). Strength of Steel Fiber Reinforced Concrete Beams. Indian Concrete Journal, Volume 48, Issue 1, 17-25.

Samarrai, Mufid A. \& Elvery Robert H. (1974). The influence of fibers upon crack development in reinforced concrete subject to uniaxial tension. Magazine of Concrete Research, Volume 26, Issue 89, 203-211. 